\title{
A Tool to Monitor and Evaluate Swimming: Development Design and Compilation of Model
}

\author{
Nur Azis Rohmansyah" ${ }^{1,2}$, Bertika Kusuma Prastiwi ${ }^{1}$, Utvi Hinda Zhannisa', Setiyawan ${ }^{1}$ and Ashira Hiruntrakul ${ }^{3}$ \\ ${ }^{1}$ Universitas PGRI Semarang, Department of Physical Education, Semarang, Indonesia, ${ }^{2}$ Khon Kaen University, Faculty of Graduate School, \\ Department of Exercise and Sport Sciences, Khon Kaen, Thailand, ${ }^{3}$ Khon Kaen University, Faculty of Applied Science and Engineer, Department of \\ Branch of Sport Science, Nong Khai Campus, Thailand
}

\begin{abstract}
Finis Tempo Trainer Pro (audible metronome pacing device) is an electronic tool used for pacing training and movement efficiency. However, it is not suitable for beginner athletes because the trainer cannot control whether the tempo of the movements made by the novice athlete is in accordance with the tempo set in the tool. A further problem is caused by the sound of the tool which is only heard by athletes so it takes awareness and honesty of athletes to match and maintain the tempo of the swimming movement in accordance with the tempo of the tool. Coaches need tools that can be used to train the efficiency of swimming movements in novice athletes. The following criteria for tools to aid in calculating the cycle of swimming movements: the sound can be heard by the coach or athlete; it can be used by more than one athlete; it also has an affordable price.
\end{abstract}

Keywords: functional state, aerobic capacity, anthropometric indicators, unarmed combat, cadets

\section{Introduction}

Swimming is one of the most suitable and enjoyable sports and entertainment activities for many people in different age ranges, especially in summer (Hossein et al., 2018). Swimming performance is influenced by a complex interaction of physiological, morphological, neuromuscular, biomechanical, and technical factors. More specifically, swimming speed is a product of stroke rate and length, and an increase in stroke rate or stroke length has been found to improve swimming performance independently (Barbosa et al., 2010a). It has been suggested that increasing swimming speed requires programmes with elements of high frequency, duration, and intensity, resulting in a high overall training volume (González-Boto, Salguero, Tuero, González-Gallego, \& Márquez, 2008). The technique done correctly will support efficient motion (Barbosa et al., 2010b). Efficient swimming movements will be easier to do with a good understanding of the technique and correct implementation of it (Wakayoshi,
D’Acquisto, Cappaert, \& Troup, 1995). One way to measure the power used when swimming is to count the number of movements performed (Girold, Calmels, Maurin, Milhau, \& Chatard, 2006). The more movements that are carried out, the greater power is used.

Finis Tempo Trainer Pro (audible metronome pacing device) is an electronic tool used for pacing training and movement efficiency. However, it is not suitable for beginner athletes because the trainer cannot control whether the tempo of the movements made by the novice athlete is in accordance with the tempo set in the tool. Finis Tempo Trainer Pro has some disadvantages when used in swimming movement efficiency training for beginner athletes; among others, in terms of the benefits of not being able to count the cycles of swimming movements, one tool can only be used for one athlete; it cannot issue sounds that can be heard by the trainer so the coach cannot control the tempo of the athlete's swimming movements; the purchase price

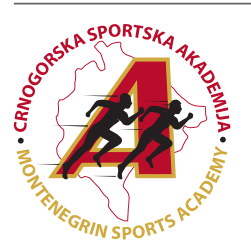

Correspondence:

Khon Kaen University, Faculty of Applied Science and Engineer, Department of Branch of Sport Science, Nong Khai Campus, Thailand E-mail: hashir@kku.ac.th 
is relatively expensive; there is a risk of leakage if used in water, and the batteries in the device cannot be replaced because doing so causes leakage in the device, so it cannot be used again in water.

Based on the weaknesses that exist in Finis Tempo Trainer Pro device and the trainer's need for tools that help develop the efficiency of the swimming motion, it is necessary to develop tools that are suitable to the trainer's needs. The purpose of this study is developing the device to aid in the efficiency of swimming movements. The tool was developed based on the previous tool, Finis Tempo Trainer Pro. Crawl swimming is the style chosen, because the cycle of swimming movements can be calculated according to the swinging movements of both legs.

\section{Methods}

The study was conducted from March to July of 2019 in a swimming pool facility located in Semarang, Indonesia. This research was approved by Universitas PGRI Semarang. Twenty-five elite national-level junior swimmers (16.5 \pm 1.2 years old) and ten professional swimming coaches. Trainer observation and athlete assessment data on the Tempo Trainer tool draft uses the answers "yes" (1) and "no" (0). Data from observations of effectiveness by swimming experts and microcontrollers on the Tempo Trainer tool can be drafted into a scale of values. Valuation ranges from "ineffective" to "very effective". The range of scores on the expert effectiveness observation sheet is a score of 1 for ineffective assessment, a score of 2 for an ineffective assessment, a score of 3 for a fairly effective assessment, a score of 4 for an effective assessment, and a score of 5 for a very effective assessment. The model arranged is considered feasible to be tested on a small scale or a large scale quantitatively calculated the score reaches a minimum standard of eligibility. Categorization norms are used in accordance with the provisions of Azwar (2011).

The validity and reliability test of the Tempo Trainer Draft was conducted using questionnaire data for trainer respondents and athlete respondents on small- and largescale trials. Validity and reliability tests were performed using Microsoft Excel 2007. The instrument in this study was a questionnaire compiled by the researcher. The compiled questionnaire is then used to provide an assessment or validation of the initial draft of the Tempo Trainer tool and observations of the implementation of field trials both small and large scale. The instrument used in assessing and analysing the appropriateness of the tool uses the PIECES (Performance, Information, Economic, Control, Efficiency, Services) analysis procedure (Turban, McLean, \& Wetherbe, 2000).

\section{Results}

After completing the revision of the draft Tempo Trainer, which was tested on a small scale, it was followed up by conducting a large-scale field trial. The implementation of large-scale trials is then observed and evaluated by swimming experts, microcontroller experts, swimming coaches, and athletes. Data obtained in large-scale trials, namely: data from observations of the evaluation of the draft Tempo Trainer by swimming experts in large-scale trials shows that all the total values obtained are categorized as good and located at intervals $\geq 51.33$. Thus, it can be con- cluded that the Tempo Trainer is a good tool; data from observations of evaluations of the Tempo Trainer draft by microcontroller experts in large-scale trials show that the total value obtained is 44 so that it is categorized as good because it lies in the $33^{\text {rd }}$ interval. Therefore, it can be concluded that the draft of the Tempo Trainer tool is categorized as good for helping the efficiency of the swinging foot movements; the observation data on the assessment of the Tempo Trainer draft by the swimming coach in large-scale trials shows that the total value of 131 is categorized as good because it is located at intervals interval 93.33. Therefore, it can be concluded that the draft of Tempo Trainer is categorized as good in helping the efficiency of Crawl swing movements in swimming. Based on these data, it can be stated that the Tempo Trainer draft is valid for use with a value of $\mathrm{rxy}=0.7945$ and from the reliability test analysis the $r$ value $=0.908$ is obtained: thus, it can be said that the Tempo Trainer draft is reliable; data from the assessment of the Tempo Trainer draft by athletes in small-scale trials shows that the total score is 142 so that it is located at an interval of $\geq 100$. It can be concluded that the athlete's evaluation of the Tempo Trainer draft is categorized as good. Based on these data, the results obtained can be stated that the Tempo Trainer draft is valid for use with a value of $\mathrm{rxy}=0.5125$, and the reliability test analysis results obtained as follows the value of $r=0.750$; thus, it can be said that the Tempo Trainer draft is reliable.

\section{Product Specification}

Tempo Trainer is a development of the Finis Tempo Trainer Pro (Audible metronome pacing device) whose main function is to set a tempo. The Tempo Trainer is programmed so that it can adjust the tempo in the form of sound or rhythm used as a reference for crawl arm movements. The rhythm in the Tempo Trainer tool consists of six types of speed, namely: speed of 30 cycles per minute, movement speed of 32 cycles per minute, speed of 34 cycles per minute, speed of 36 cycles per minute, five (5) speeds of 38 cycles per minute, and speed 40 cycles per minute. The results of the calculation of arm movements will be displayed numerically on the LCD screen. The sound of Tempo Trainer can be heard by the trainer through speakers designed to be attached to the box. The use of this tool must be accompanied by an underwater speaker so that it can be heard by athletes from underwater.

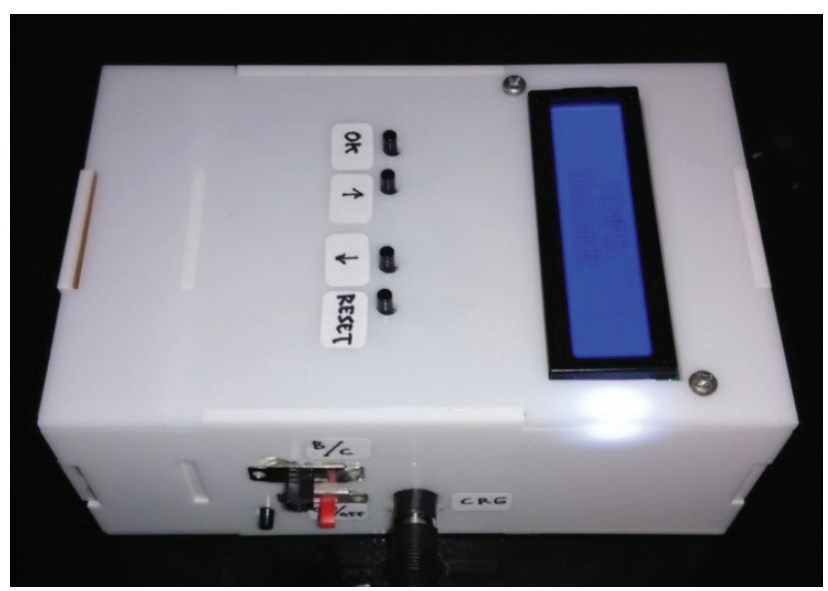

Figure 1. Tempo trainer Pro development 


\section{Discussion}

The results of the development of the Tempo Trainer tool to help the efficiency of freestyle arm movements in the sport of swimming suggest that the tool can be mass-pro-

\section{Acknowledgements}

The authors wish to thank Kementerian Riset, Teknologi dan Pendidikan Tinggi of Indonesia (Ministry of Research, Technology and Higher Education of Indonesia) and Universitas PGRI Semarang, Central Java for the scholarship.

\section{Conflict of Interest}

The authors declare that there no conflict of interest.

Received: 14 December 2019 | Accepted: 19 January 2020 | Published: 01 February 2020

\section{References}

Azwar, S. (2011). Reliabilitas Dan Validitas. Yogyakarta: Pustaka Pelajar.

Barbosa, T.M., Bragada, J.A., Reis, V.M., Marinho, D.A., Carvalho, C., \& Silva, A.J. (2010a). Energetics and biomechanics as determining factors of swimming performance: Updating the state of the art. Journal of Science and Medicine in Sport, 13(2), 262-9. doi: 10.1016/j.jsams.2009.01.003

Barbosa, T.M., Costa, M., Marinho, D.A., Coelho, J., Moreira, M., \& Silva, A.J. (2010b). Modeling the links between young swimmers' performance: duced. This is related to the opinion of some coaches who want the tool to add equipment owned by the swimming association to support training and facilitate the trainer in training the efficiency of freestyle leg movements.

Energetic and biomechanic profiles. Pediatric Exercise Science, 22(3), 379-91. doi: 10.1123/pes.22.3.379

Girold, S., Calmels, P., Maurin, D., Milhau, N., \& Chatard, J. C. (2006). Assisted and resisted sprint training in swimming. Journal of Strength and Conditioning Research, 20(3), 547-54. doi: 10.1519/R-16754.1

González-Boto, R., Salguero, A., Tuero, C., González-Gallego, J., \& Márquez, S. (2008). Monitoring the effects of training load changes on stress and recovery in swimmers. Journal of Physiology and Biochemistry, 64(1), 1926. doi: 10.1007/BF03168231

Hossein, M., Norouz, M., Nazari, F., Zohreh, A., Mojtaba, S., \& Ali, E. (2018). An Investigation into the Status of Water Quality Health Indicators of the Swimming Pools in Tehran in 2015. Annals of Medical \& Health Sciences Research, 8(2), 105-110.

Turban, E., McLean, E., \& Wetherbe, J. (2000). Information Technology for Management: Transforming Organizations in the Digital Economy: Wiley

Wakayoshi, K., D'Acquisto, L.J., Cappaert, J.M., \& Troup, J.P. (1995). Relationship between oxygen uptake, stroke rate and swimming velocity in competitive swimming. International Journal of Sports Medicine, 16(1), 19-23. doi: 10.1249/00005768-199505001-00155 